\title{
Ethnologies
}

\section{Popular Music as an Interpretive Device for Creating Meaningful Visitor Experience in Music Museums}

\section{Kathleen Wiens}

Volume 37, numéro 1, 2015

Exposer les paysages sonores

Exhibiting Soundscapes

URI : https://id.erudit.org/iderudit/1039659ar

DOI : https://doi.org/10.7202/1039659ar

Aller au sommaire du numéro

Éditeur(s)

Association Canadienne d'Ethnologie et de Folklore

ISSN

1481-5974 (imprimé)

1708-0401 (numérique)

Découvrir la revue

Citer cet article

Wiens, K. (2015). Popular Music as an Interpretive Device for Creating Meaningful Visitor Experience in Music Museums. Ethnologies, 37(1), 133-151. https://doi.org/10.7202/1039659ar
Résumé de l'article

Cet article examine les modes sur lesquels les visiteurs s'investissent en contexte muséal consacré à la musique. En tant que conservatrice d'un département muséal consacré à la musique européenne, j’ai pour tâche de représenter les cultures musicales de l'Europe en fonction d'entités géopolitiques, de groupes communautaires et de genre. Je présente une étude de cas dans laquelle la musique populaire a servi à connecter les visiteurs au contenu exposé en suscitant leur intérêt et en créant pour chaque visiteur le sentiment d'un contexte personnel. En présentant aux visiteurs des contenus audiovisuels qui avaient un sens pour eux, j'ai pu prolonger les temps de visite de certaines expositions en particulier. Dans ces cas, j’ai employé la musique populaire comme un outil didactique pour orienter les visiteurs vers une compréhension critique de la culture. Cela m'a permis de simplifier et de représenter efficacement les nuances du comportement musical et les concepts de localisation, d'innovation et de fluidité. Les découvertes permises par ce projet ont stimulé la réflexion et les questions relatives aux finalités et aux méthodes de représentation au sein des espaces muséaux exposant des instruments de musique.
Ce document est protégé par la loi sur le droit d'auteur. L'utilisation des services d’Érudit (y compris la reproduction) est assujettie à sa politique d'utilisation que vous pouvez consulter en ligne.

https://apropos.erudit.org/fr/usagers/politique-dutilisation/ 


\title{
Popular Music as an Interpretive Device for Creating Meaningful Visitor Experience in Music Museums
}

\author{
Kathleen Wiens \\ Canadian Museum for Human Rights, Winnipeg
}

This article suggests popular music as a mode of engaging visitors with museum-based musical instrument collections, and it provides a case study that demonstrates popular music as an effective interpretive device. ${ }^{1}$ As a curator for a large gallery space (approximately one thousand objects) I found that popular music piqued curiosity in visitors, created a personal relatable musical experience, and motivated visitors to engage with didactic display content and thus access information that was previously unknown to them. ${ }^{2}$ My initial goal had been to use popular music as a way of creating nuance within a museum taxonomy that misrepresented musical activity in Europe as contiguous with state borders. The resulting success for visitor engagement led to me understand how interpretation rather than information engages visitors, and how museum display space dedicated to musical instruments might benefit from broadening their pool

1. Following Simone Krüger (2009: 165), I utilize the term "popular music" in a broad sense as "all sorts of different music that are present in popular culture warranted by its producers, makers, listeners, consumers, etc." This includes songs of any commercially available music genre (rock, pop, metal, folk revival), as well as music embedded within pop culture forms such as advertising jingles, movies or television series. My concept of the term is less concerned with genre or classification and more with global consumer reach - quite literally its popularity. I form my concept by asking the following two questions: Might the music in question be easily identifiable by the visitor, whether by style or "feel," or by aural or visual cues such as a melody or a movie character? Will the visitor quickly recognize a band, song, style, movie or TV series; in other words: is there likely a pre-existing knowledge for the music in question?

2. "Museum speak" often differentiates didactic content (that which is intended to transmit a message) from aesthetic content (that which is solely for beauty and visual intrigue). 
of interpretive devices in order to inspire interest and a sense of meaning for non-specialist visitors. ${ }^{3}$

My perspectives on visitor engagement were shaped through my current position as interpretive planner at one of Canada's national museums and before that, three years working as Curator of the European collection and gallery at the Musical Instrument Museum in Phoenix, Arizona (hereafter referred to as "MIM"). ${ }^{4}$ As an "applied ethnomusicologist" (see "ICTM") I deploy ethnomusicological knowledge in the public sphere, work which involves practical action and affects "the cultural flow of music throughout the world" (Titon 1992:315). In my daily work, these tasks are informed by my belief in "the value and use of music to foster intercultural acceptance and understanding" (Higgins 2012:5), a belief which aligned with MIM's mission and mandate ${ }^{5}$ and which informed my curatorial decision-making.

The relationship between visitor experience and personal identity has been explored in numerous public interpretive spheres, such as nature conservation sites, science museums, children's museums, visitor-centric art and artifact museums, and public history sites (see Falk 2009; Falk and Dierking 1992; Simon 2010; Tilden 1957). As with many interpretive planners working in North America, the work of Freeman Tilden's 1957 book Interpreting Our Heritage inspires and shapes my understanding of the significant role interpretation plays in creating personal, meaningful visitor experience. Tilden's message is simple, and I summarize it in my own words here: by revealing to visitors a message with which they can personally identify, you will provoke curiosity, followed by understanding. Through understanding, you will foster appreciation, and through appreciation you will stimulate concern. Through concern, you will kindle a desire to protect.

3. I wish to thank Roger Mantie, Katherine Palmer, and Randi Ringnes for their input to this article.

4. The terms "messaging" and "interpretive devices" appear frequently throughout this manuscript. These terms are central to the practice of interpretive planning. "Messaging" refers to the primary concepts that one wants the museum visitor to encounter, consider, and remember (sometimes also called a "takeaway" or "the big idea"). "Interpretive device" refers to any text, image, design feature, audio, video, or architectural feature intended to reveal those messages to the visitor.

5. From mim.org: "The Musical Instrument Museum (MIM) enriches our world by collecting, preserving, and making accessible an astonishing variety of musical instruments and performance videos from every country in the world. MIM offers guests a welcoming and fun experience, incomparable interactive technology, dynamic programming, and exceptional musical performances. MIM fosters appreciation of the world's diverse cultures by showing how we innovate, adapt, and learn from each other to create music_-the language of the soul." 
Guided by their own personal experience, visitors will seek (and therefore must find) content with which they can identify (this does not mean that an object or content has to be familiar, but rather that some aspect of an object or content "speaks" to one of their identity needs, see Falk 2009 and Tilden's Chapter II). That personal connection makes the content meaningful for them (regardless of its familiarity), and through that meaningful encounter the visitor will have their worldview affirmed or challenged by the new knowledge they encounter. Falk and Dierking (2004) call this a "contextual model of learning," in which pre-existing knowledge ("context") acts as a foundation upon which new information can be built and will be maintained after the museum visit. "Meaning that is made in museums is framed within, and constrained by, prior knowledge, interests and beliefs...In a very real sense, the knowledge and experience gained from museums is incomplete: it requires enabling contexts to become whole" (Falk and Dierking 2004: 141-142). This interest in visitor experience is part of an ongoing trend towards "visitor-centric" museums - institutions that prioritize the people walking through their doors rather than only prioritizing a collection or research agendas of "insider" professionals. In previous generations museums acted as cultural authorities and therefore invoked display methods that established distance (physically or intellectually) between visitor and object. Visitor-centric museums conceptualize themselves as social entities that exist to enrich and be enriched by their communities. In The Participatory Museum, Nina Simon (2010: 127) conceives of an object not for "artistic or historical significance but for its ability to spark conversation," that "[every] museum has artifacts that lend themselves naturally to social experiences" by inspiring dialogue between visitors and between visitor and museum. Simon's work is one among many who prompt and challenge museum professionals to constantly be re-evaluating what we do and why we do it.

With only a few exceptions, museum-based musical instrument collections have not taken advantage of contemporary museological thought, and only in recent years have some of the major collections reevaluated messaging and interpretive devices from those that were handed down to us from the previous century. Based on my visits to most of North America's major music museums and many in Europe, I am prompted to ask questions about "our" approach to interpretation (by "our" I mean my own and that of other museum professionals responsible for representing music in museums). What messaging and interpretive devices do we currently invoke, and why? What messages and interpretive devices could 
and should we consider? In interpretive planning circles, a "list of facts" is the least ideal of all approaches to messaging and interpretation (title, date of manufacture, name of maker, materials, organological category, and perhaps a few sanitized statements about context). Yet, because of an inherited legacy, this is the interpretive approach that musical instrument museums fall into by force of habit. From my perspective, this is to our own detriment.

My findings do not offer solutions that fit every institution's scope and mission. They are aimed to spur dialogue on the creation of meaningful music museum experiences for visitors outside of a circle of connoisseurs. My hope is that this project will serve as an additional step towards constructive, mutually beneficial dialogue between the fields of organology and ethnomusicology for the sake of maintaining the relevance of collections for visitors.

\section{Popular music and the "inherited paradigm" of musical instrument museums}

Until the 2000s the predominant model of museum-based musical instrument exhibition could be better described as "display" rather than "interpretation." In Europe and North America, display concepts dated back to museum models from late $19^{\text {th }}$ and early $20^{\text {th }}$ century fine art, ethnographic, and scientific (in particular animal biology) museum. I call this the "inherited paradigm." This paradigm for collection and display was established and perpetuated by museum-based musical instrument collections such as the Musical Instrument Museum in Brussels (Belgium), the Cité de la Musique in Paris (France), the Museum of Fine Arts in Boston (USA) and the Metropolitan Museum of Art in New York (USA). These collections emerged according to value constructs among affluent collectors of the same time period, and their museum representation was steeped in assumptions that cultural authority was held by the collection and its professionals to then be bestowed upon the visitor. They include instruments of Western European salon and concert-hall music with a sprinkling of exoticist "ethnic" objects. Their raison d'etre was comparative study, collection building and - following art and artefact museums of the $19^{\text {th }}$ and $20^{\text {th }}$ centuries - as "preserver and protector of the rare, the unique, the beautiful" (Skramstad 1999: 113). This approach to collection and display assumed that by mimicking museums of science or fine arts one could assert musical heritage as worthy of museum display and preservation. Display parameters of the early collections followed $19^{\text {th }}$ century notions of 
how visitors should experience museum content. Objects were (and some still are) displayed against walls or within glass cases typically filled to the brim, to be admired for their visual assets or as signifiers of an evolution.

The interpretive approach of the inherited paradigm mirrored the research of our organological and ethnomusicological ancestors VictorCharles Mahillon (1841-1924), Curt Sachs (1881-1959), and Erich von Hornbostel (1887-1935). As early proponents of systems of musical instrument categorization, these scholars believed that imitating the scientific world would bring music studies - including interest in global music - into the "fold" of academic scholarship (see Kartomi 1990). It is, therefore, not surprising that most musical instrument museums did (and many still do) represent instruments through the lens of the $19^{\text {th }}$ century: fixation with classifications and dividing "the West and the Rest" (non-European instruments or instruments connected to popular music performers and manufacturers are usually represented in peripheral gallery space from the European "classical" instruments). Objects may be accompanied by text on labels, usually identifying instrument name, maker, date of manufacture, and organological information (materials, classification). A sentence or paragraph may outline historical or contextual information. Overall, the messaging and interpretation in European and North American musical instrument museums remain caught in modes of the early century, and steeped in terminology and narratives that are important to "insider" experts. They have managed to skirt the critiques and ideas proposed by modern museology discourse to the extent that some have become museums of museums. As worst-case scenarios, a few museum-based collections lost integral status within their institutions and communities and have been relegated to storage in favour of more "trendy" collections using limited and much sought-after display space. Only a few institutions have re-shaped messaging and interpretation to represent global, popular, or contemporary content as integral to one another or to represent objects as part of social behaviour and identity formation. ${ }^{6}$

6. The motivations and capacities for museums to change during recent decades are much more nuanced than the space of this short article allows me to describe. At the time of this article's publication, several museum-based collections are undergoing gallery redesigns. Several have, in the past decade, integrated audiovisual (AV) components or explored new technology and modes of storytelling. A handful of collections that previously followed the inherited paradigm have broadened their interpretive approach through hands-on interactive elements, in-house or outreach educational programming, and live performances where visitors hear and observe instruments in action (this, of course, requires that visits coincide with performances). 
Museum-based representation must and is changing in order to maintain relevance and sustainability - are the changes taking place with an eyeswide-open approach, or do they continue to be self-referential?

Since the 1990s, popular music has, by and large, created a space for itself outside the inherited paradigm museum experience. Museums of popular music are the newcomers to the neighbourhood of music museums. Popular music museums symbolize a desire to assert popular music as "museum worthy" and to do so through new modes of museum-based teaching and learning. They include the Rock and Roll Hall of Fame in Cleveland (U.S.A.), Rockheim in Trondheim (Norway), ABBA the Museum in Stockholm (Sweden), and Seattle's Experience Music Project (U.S.A). They explore new paradigms for representing music in museums. Their interpretation establishes resonance and meaning with visitors, by appealing to fandom, nostalgia, and personal taste. They provide learning experiences that are participatory (hands-on interactives) and immersive (for example, singing in a mock "recording studio," or entering a fabricated home garage rock-band practice space). The approach to instruments for display purposes is to integrate them alongside paraphernalia, text, and AV in a supportive rather than central role within the visitor experience. The lessons taught through such museums include musical elements (creating rhythm, chords, or melodies) or lessons about a specific musician or style.

From an interpretive standpoint, one thing that these museums do well is recognize that what "we" as insider professionals find important may not be what is meaningful to our visitor. They understand the importance of a human story. They invoke the images, sights, and sounds of people "doing stuff" with which our visitors can easily connect. An almost total disconnect between popular music museums and "inherited paradigm" museums is something akin to two cousins who share a bloodline but are rarely on speaking terms. And yet, the inherited paradigm has much to learn from museums of popular music in terms of interpretive approaches and visitor engagement. Which alternative paths can we explore that will bring non-experts into our stories in ways that reveal the magic of musical instruments already recognized by specialists? What new stories might we consider weaving around our objects that will engage and enthrall our visitors? What resources lie waiting for us to be used as interpretive devices?

\section{A curatorial quandary}

Opened in 2010, MIM is part of an emerging paradigm of visitor-centric 
music museums. As a museum that explores music through a global lens and as social behaviour, MIM draws heavily from the field of ethnomusicology to inform its content. Content creation at MIM is by-and-large created by curatorial staff with some input from design and education teams. The process for content creation is as follows: MIM curators first establish a display's message and create text to support the message, followed by sourcing or evaluating objects, images, and AV according its relevance to the message and narrative. Because MIM is a visitor-centric museum, the impetus for the curatorial staff is interpretation for the sake of enriching the visitor experience and knowledge. MIM curators perform their own interpretive planning and use language, objects, and AV to interpret message in ways that will make messages interesting and engaging to a non-specialist public.

For museum employees, constraint is a catalyst for creativity. Museum institutions usually adhere to specific guidelines for language (style and word count), exhibition design, thematic scope, and visitor experience. The limitations of in-house guidelines pose a creative challenge for the professionals tasked with content creation. Such was the case at the Musical Instrument Museum in Phoenix (MIM), and I found their inhouse parameters both a welcome and frustrating creative challenge (I suspect that my ambivalence towards display parameters puts me in the same category as many museum professionals). MIM adheres to specific guidelines for text length and placement, object placement, images, and audio-visual content. The parameters favour brevity. Individual displays have a 125 maximum word-count aimed at a grade 8 level according to the Flesh-Kincaid readability test, and may include up to three images and four 30-second audio-visual (AV) clips. AV brings the objects to life by allowing visitors to see and hear music makers and their musical objects in action, and are viewable by the visitor on large screens embedded within each display. Audio is heard through individual headsets, broadcast via radio signals transmitted from inside each display. The display guidelines were set with consideration for the size and scope of the institution and its potential to overwhelm the visitor with information (MIM has over 8,000 objects within approximately 300 displays, and an average visit time is 3.5 hours). With display parameters in mind, not all musical stories can be told and thus a designated display supports only one or two messages.

At MIM, Musical cultures are represented in five main galleries (titled: Africa, Asia, Latin America, North America, Europe) and two sub-galleries (Middle East, Oceania). In each gallery, a country-by-country 
display taxonomy helps structure the visitor's self-guided path by allowing visitors to simultaneously orient themselves spatially within the museum and geographically within the planet. Amid the state-by-state displays each gallery contains a few thematic displays. For example, the Europe gallery includes Roma, Violin Makers of Cremona, and Franciolini's Forgeries. From my own critical perspective as a specialist in European cultural nationalism, the political state as a category through which to represent culture is a highly problematic taxonomy. By selecting political state as a category through which to present European cultural practices, MIM risks re-enforcing highly problematic ethno-national understandings of the relationship between state and culture (understandings which claim human musical behaviour and state boundaries as congruent). The country-by-country taxonomy risks representing Europe - and the world - as a collection of musical cultures neatly contained within geo-political boundaries. Musical practices rarely fit neatly within a geopolitical boundary. The "nation-state" as the primary form of polity emerged in its European forms only in the early $20^{\text {th }}$ century, and national boundaries have been in near-constant flux since they were first drawn. MIM curators, therefore, must be strategic if wishing to represent anything aside from what might be perceived by visitors as a hegemonic or "majority" culture in a given country, especially when the risk is characterizing a given country only according to a majority culture. In many cases I noted that our domestic visitors have minimal basic knowledge of the location and names of Central and Eastern European countries. We would, therefore, do a disservice to our visitors if we fed their unfamiliarity with essentialism. I had no desire to represent music cultures in ways that perpetuate essentialism or that normalize a relationship between a state and a majority musical tradition, issues identified by scholars of music and national identity (Ceribaši 2000; Ceribaši and Haskell 2006; Pettan 2007; Seeman 2012; Slobin 1996; Žani 2007). In doing so I would commit the same erasures and manipulations that have plagued the continent since the disintegration of empires and the emergence of nation-states: the omission of musical communities and practices that did not suit state political agendas and therefore led to cultural practices of "undesired" linguistic, cultural, or religious groups' being marginalized. On top of this, the notion of "Europe" as an identity and entity remains contentious within countless political, economic, and cultural discourses.

The potential issues created by MIM's taxonomy become a curatorial challenge as I attempted to represent music in Europe as a complex picture contingent on migration, communication and trade routes, and linguistic, 
cultural, taste, religious, and social communities. The perspectives of ethnomusicology lent themselves well to navigating this potentially problematic situation. Instead of trying to solve what could be an unsolvable quandary, my ethnomusicology background gave me the tools to subtly point towards nuances. Popular music proved extremely helpful in this endeavour. By pairing display instruments with specific AV selections I was able to circumvent museum-mandated display parameters and problematic taxonomies. Instead, I was able to represent a continent of cultural zones and pockets and of fluid, changing, dynamic, and inventive practices.

\section{Examples from Austria and Latvia}

Though I refer to this as one case study, it contains examples from three display spaces: two from Austria and one from Latvia. The additions I made to Austria and Latvia were implemented and tracked from a defined start date and purposeful follow-up observation to make note of visitor reaction. In all three examples I utilized objects, AV, and images to reveal messages about locality or regionalism, creativity, continuity, adaptability, innovation, and the flexibility of categories such as "folk," "classical," and "pop."

Austria

While creating content for "Austria," I settled on two thematic messages: the first was "technological innovation" and the second "gemütlichkeit," an important concept in Austrian life meaning closeness and good feelings among friends. Though I represented both concepts as relating to local or regional practices rather than as Austria-wide phenomena, there are certainly practitioners and fans of both types of music throughout Austria and the world.

MIM's "Austria" display includes a selection of $18^{\text {th }}, 19^{\text {th }}$ and $20^{\text {th }}$ century Vienna-made brass instruments by makers Dehmal, Votruba, Kerner, and Uhlmann, and one Vienna horn made by the Yamaha company of Hamamatsu (Japan). The messages of this display are of innovation, simultaneously local and global identities, and the movement of orchestral music from performance hall to film soundtrack. The late $19^{\text {th }}$ century was a particularly active time for brass instrument manufacturers in central Europe. Vienna-based makers and manufacturers developed their own particular valve technology, bore size, tubing length, and additional crooks to create the "Wiener horn" [Vienna horn], a French horn with particular 


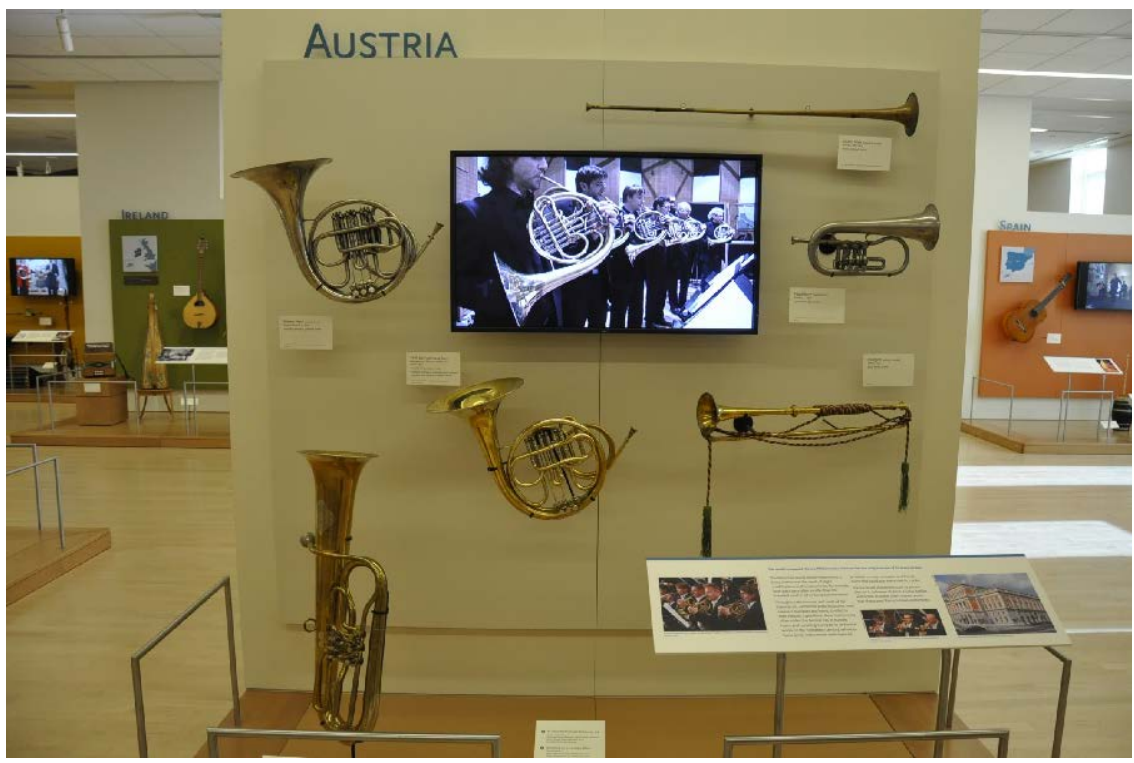

Image 1. Austria display area featuring Vienna Horns, Musical Instrument Museum, Phoenix, 2015. Photograph by Kathleen Wiens.

sound colour and playing style that came to be associated with Viennabased orchestral ensembles. AV selections include two performances of brass-heavy orchestral excerpts by Gustav Mahler and Anton Bruckner, and a third video selection by the "Vienna Horns" chamber ensemble. The Vienna Horns ensemble is made up of Austria-based Vienna horn players performing arrangements of folk song, orchestral repertoire and film scores. I obtained permissions to use a video performance of their arrangement of Alan Silvestri's 1985 theme from "Back to the Future" (arranged by Alexander Wagendristel). ${ }^{7}$ The melody from this work is widely recognized in North America due to the ongoing popular appeal of the "Back to the Future" film series.

Located adjacent to the "Vienna Brass" display is a display dedicated to folkloric music in Austria. The display represents "Schrammelmusik," a genre of marches, polkas, and waltzes with specific instrumentation (doublenecked guitar, violin, and clarinet, among other possible additions). ${ }^{8}$

7. Viewable at https://www.youtube.com/watch?v=jnFl1qOIYTA

8. The example of Schrammelmusik brings out the problems of delineating music by genre. Schrammelmusik in its heyday was a type of popular music, but now might be classified as either "classical" or "folk" music according to its modern contexts, instrumentation, compositional or performance style (with additional consideration that several Vienna-style yodelers are also trained operatic singers). 


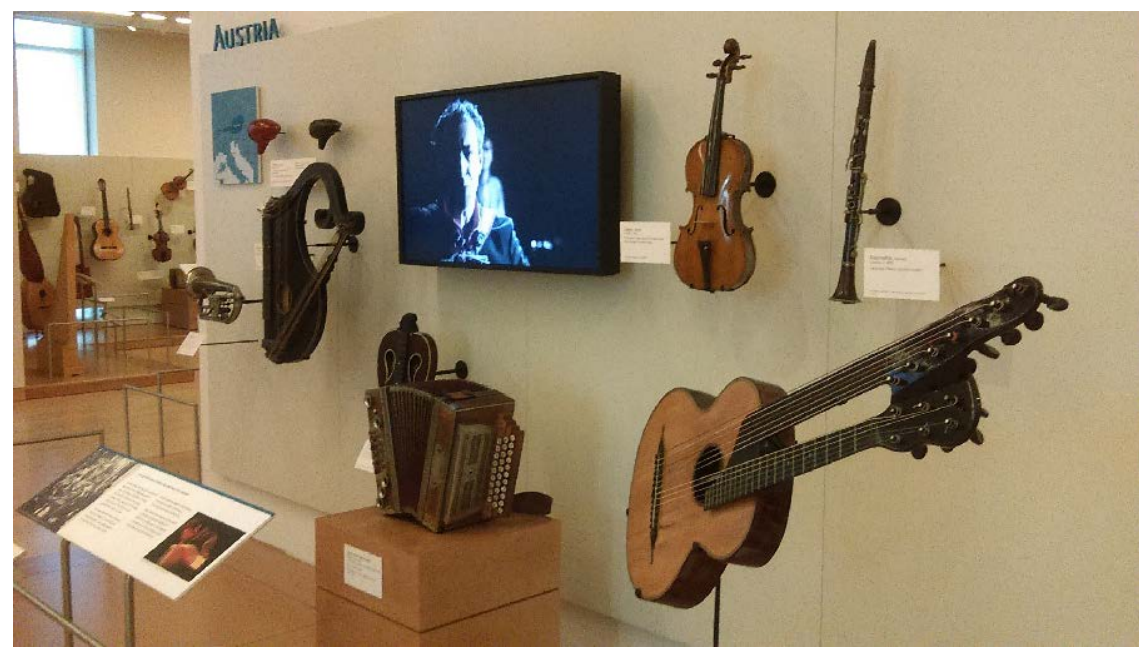

Image 2. Austria display area featuring Hubert von Goisern, Musical Instrument Museum, Phoenix, 2015. Photograph by Kathleen Wiens.

The compositions of brothers Johann and Josef Schrammel came to be associated with songs in Viennese dialect and with public venues such as popular heuriger wine taverns. Wine taverns continue to be common places to meet, eat, and enjoy company of good friends (gemütlichkeit). The display incorporates historical instruments similar to those still in use by contemporary folk musicians: a 1903 Vienna-made violin, an 1880 clarinet, and an 1889 double-necked Kontragitarre [contraguitar] by maker Ludwig Reissinger of Vienna. AV content for this display includes a performance by a modern-day Viennese Schrammel ensemble and a segment of a song by Wiener dudler [Vienna-style yodeler] Agnes Palmisano accompanied by an accordionist and contraguitarist.

A third video, "Brenna tuats guat," [It burns good], written and sung by folk-rock musician Hubert von Goisern, completes this display's video selections. ${ }^{9}$ Von Goisern made a name for himself as a "Neu Volksmusik" or "Alpine rock" singer in the 1990s, most notably as frontman of the "Alpenkatzen" band. Brenna tuats guat is a fast-paced rock-polka song which made it to the number one position on the Austrian pop charts in 2013. Goisern sings in a regional Tyrolean dialect. His primary instrument is a Steirische harmonica [Styrian accordion] made by "Novak" maker based in

In practice, musical sounds and musicians themselves flow freely between perceived categories, making my classification of this style as "popular music" admittedly problematic.

9. Viewable at https://www.youtube.com/watch?v=1-XYBJOKNMg 
Klagenfurt. ${ }^{10}$ The videoclip in addition to an image of von Goisern playing his Novak accordion complement the late $19^{\text {th }}$ century Styrian accordion on display (maker Franz Lubas of Windischgraz, formerly in Austria, now in Slovenia).

\section{Latvia}

Creating one focused narrative per country is not always possible due to floor plan considerations. One such example was MIM's display space for the Baltic countries (Latvia, Lithuania, and Estonia). These three countries share one display platform, a single AV monitor, and two text panels. A solution formulated by my predecessor was to isolate a narrative that was common within the three states. The narrative supported by text, images, and AV speaks to revitalization of local and regional vocal and instrumental performance in post-Soviet folklore festivals. AV content includes examples from staged folkloric performances in the three countries, some rooted in historic practice indicated by the use of folk instruments, and others injected with pop flavours indicated by the integration of drum kits and other contemporary instruments. I added one AV selection, a video documenting a 2010 "flash mob"-style music performance in Riga

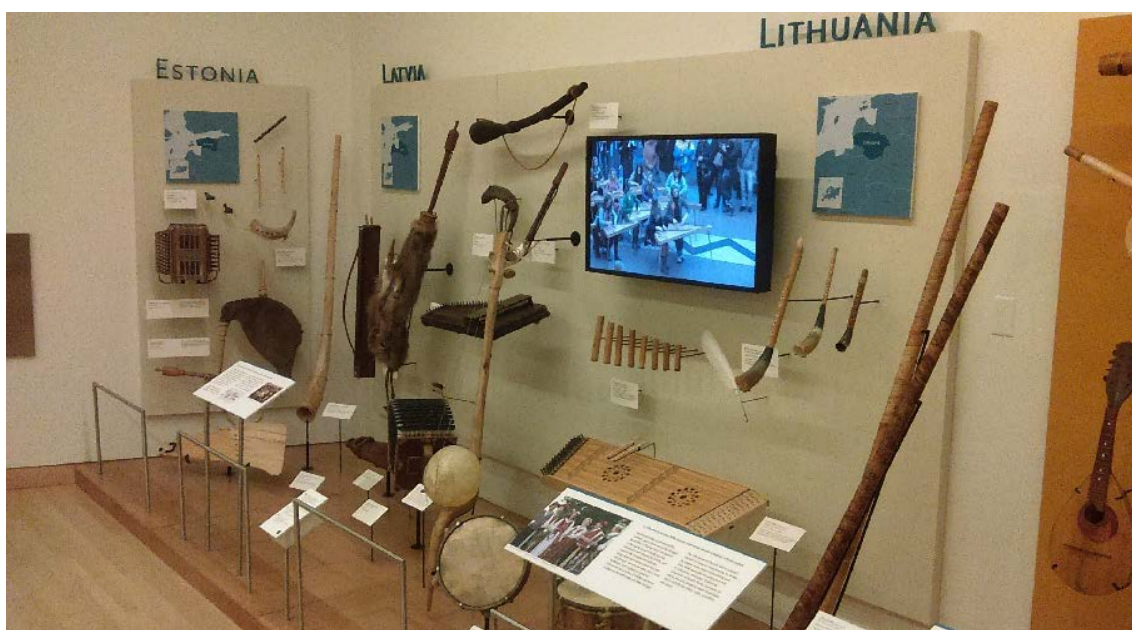

Image 3. The Baltic states' display featuring kokle flash mob performance, Musical Instrument Museum, Phoenix, 2015. Photograph by Kathleen Wiens.

10. The Styrian accordion, a diatonic accordion with an expanded bass sound, is common in Alpine and Tyrolean regions in central Europe. 
Station (the central train station of Riga, Latvia) organized by the Latvian National Centre for Culture. ${ }^{11}$ The performers are adolescent girls, singing and playing kokle (a plucked folkloric zither played horizontally across the lap). In keeping with flash mob-style performances made popular in the early 2000 's, the musicians appear one by one in a public area, casually assemble their instruments as they arrive, and begin playing. At the climax of the event there are approximately 24 kokle players and several percussionists. The musicians sing and play folk songs and popular songs, one of which is the 1968 Beatles hit "Hey Jude" (composed by Lennon and McCartney). I selected this song because it is widely recognized in North America and appeals to several generations of visitors because of its continuing popularity. In contrast to the display's over-arching narrative, the video suggests that folk instruments are not confined to formal stage performance but are adaptable to daily life and to popular culture behaviours - in this case the flash mob style of unannounced performance in public spaces.

\section{Results}

Popular music proved effective in eliciting curiosity, drawing visitors towards a display, and maintaining their attention. When compared with previous visit length statistics, all three displays show increased visit times. ${ }^{12}$ The display for "Austria: Vienna Brass" shows an increase from 19 seconds to 27 seconds for an average visit; Austria's folkloric display shows an increase from 17 to 27 seconds; Latvia's shared AV screen visit time increased from 39 to 52 seconds. These video clips acted as audible "beacons," drawing visitors towards a display. During in-gallery observation I noted numerous instances of visitors walking with intention in one direction but, upon hearing the familiar tune in their headset, they turned and moved towards that AV screen. Visitors often reacted vocally, by uttering words that indicated that the tunes were familiar or attractive to them: "check out this polka" (a reference to the rhythm of the van Goisern tune), or "they're playing Hey Jude," or "they're playing Back to the Future." I noted visitors reacting physically (usually with dance-like gestures) to the Hubert von Goisern polka beat and to the Wiener dudler. From statistics and from my own time observing visitor behaviour, I conclude that popular music instigates curiosity and serves as a meaningful point of entry. One encounter with a visitor engrossed in the "Hey Jude" video, who also happened to be wearing a Beatles T-shirt at the time, reinforced to me the importance of providing

11. Viewable at https://www.youtube.com/watch?v=gJRR4rrsw7s

12. These statistics are available through the radio frequency-based head set technology which tracks numbers and visit times of people at each display. 
content that is meaningful in ways not only defined by a curatorial agenda, but according to an honest appraisal and understanding of our visitors.

The biggest hurdle is establishing in concrete terms whether or not visitors interpreted the intended messages of innovation, adaptability, continuity, or local or regional musical identities. I was unable to conduct in-gallery person-to-person surveys to gauge visitor interpretation (that step could not occur due to several circumstances). However, I was able to spend time in the gallery and watch visitors' physical reactions and movements, and that, in itself, helped me to understand the effectiveness of my approach insofar as attracting and exciting visitors for a specific display.

In this case, popular music served as an interpretive device that simply and effectively resolved a curatorial quandary. It allowed me to work around restrictive display parameters and a problematic taxonomy by adding nuance to otherwise narrow, potentially misleading and generalist categories. For the moment I remain content that, at the very least, I represented musical cultures in ways that do not re-enforce geopolitical and cultural boundaries as congruent. The greater interpretive "win," however, was seeing firsthand why it is important to invite visitors into the stories before them, and the effect that invitation can have on visitor experience. As a tool for visitor engagement, popular music attracted and excited visitors and brought them towards specific messages.

\section{Why was it "popular"?}

Was this experiment successful solely due to the recognizable nature of the examples I used? What other factors may have been at play?

There are many compelling points of engagement in museums that can spark curiosity, motivate learning, and create meaning. Within my Europe gallery, many examples of music that could not be classified as "popular" (according to my qualifications) garnered similar reaction to the popular music in terms of verbal commentary by visitors, movement in time with the beat, and increased listening times. Two such examples involve a quick-paced kolo dance performance from Leskovac (southern Serbia) and an up-beat teasing song and a klezmer tune from Belarus. These clips "out-perform" other segments in their respective displays as far as attracting visitors and eliciting their excitement. Objects also act as beacons for the curious museum goer: the double-necked contraguitar in the Austrian folkloric display was a favourite stopping point for guitar aficionados. The attractive look of shiny brass instruments in the Austrian brass display 
certainly motivated visitors to approach that display.

Where popular music had the advantage over these examples is that it provided personal connection for the visitor and helped them self-situate within previously unfamiliar musical cultures they encountered. Popular music is an acknowledged catalyst for learning (Burn and Martinez 1993), for initiating critical thought about cultural processes (Zemke-White 2006), and acting as a powerful didactic tool through which personal identities are woven, constructed, and contested (see McCarthy et al. 1999). As a site of individual identity construction, popular music offers "experiences which enable us to place ourselves in imagined cultural narratives" (Frith 1996: 275).

As a museum-based project this study represents a departure from the focal points of scholarship on popular music, which typically use popular music as a site for cultural studies discourse or as a teaching tool for musical elements or self-expression in formal pedagogical settings (see Mantie 2013). Without the structure of a formal teaching and learning situation, creating museum content is an art form unto itself. Museum professionals subtly balance the needs of learners of all age groups and identities. We attempt a massive challenge of creating "musical knowing" (Higgins 2012:4) within the malleable and self-guided nature of the museum gallery experience, often with only a 30 - to 60 -second timespan in which to make an impact before the visitor moves along to the next display space or object. These constraints motivate creative ways of thinking about how we send messages. The success of these examples motivated me to invoke popular music and popular culture references throughout the gallery, each time followed by notable increases in visitor engagement.

Popular music excites visitors because it is content they already know and already hold dear. It is, therefore, a meaningful point of reference for visitors - an "entryway" that establishes familiarity and comfort. This is not merely a question of pandering to nostalgia or popularity; it is a matter of effectively harnessing its power for didactic purposes. Its power and capacity for nostalgia acts as a receptor for new information. "Mass appeal" and "nostalgia" need not be shied away from as ways of reaching an audience; meaningfulness to visitors can be co-opted in service to teachable moments and as an entryway towards critical thought on cultural processes. Popular music need not act as a supplemental or peripheral story, but can drive content that challenges pre-conceived understandings of human musical behaviour. 


\section{A need for dialogue}

During my North America and many in Europe, I have noted a massive oversight in messaging and interpretation as handed down through the inherited paradigm. Quite simply, their messaging and interpretation disregards human action and ignores human (visitor) curiosity for "people doing stuff': what people do and why they do it. Humans latch on to stories about beings "doing stuff" ("beings" as in human being or animal, but in this case human is most relevant). The irony if not disconnect of this situation is that music is a social behavior, and museum going is also (very often) a social experience. It seems that, as a nexus of two social phenomena, our institutions would be ideal to tap into public curiosity and enthusiasm for music and stories. Earlier in this article I noted that dialogue between popular music museums and museums of the inherited paradigm could hold potential benefits for music museum visitor experience. I conclude by pointing out one additional relationship in which further conversation might strengthen the pathway towards visitor-centric interpretation and therefore meaningful visitor experience. When I consider the shared roots of ethnomusicology and organology in music scholarship of a previous century (such as Erich von Hornbostel and Curt Sachs) it seems unfortunate that the disciplines have - for a number of reasons - become separated if not almost estranged from one another with only a few exceptions (examples such as Bates 2012; Kartomi 1990; Lindsey and Roda 2014). My own understandings of global music cultures have certainly been enriched by exposure to the object-centric inquiry of organology, and the fledgling understandings I have gained in regards to material and object conservation has strengthened my role as a museum professional. When objects in museums become a portal to stories and conversations about human behavior, they ultimately serve as a portal through which individual visitors have their worldviews both affirmed and challenged. From the perspective of interpretation, worldview affirmation and challenge is key to creating a sense of relevance of our collections for museum visitors. Music making and instrument making are behaviors rich in fundamental human experiences with which a public of even the most diverse interests and experiences can connect: empowerment, innovation, overcoming obstacles, and enacted rituals of the life cycles all humans experience. Instruments and sound are a result of human action; their stories do not make sense if isolated from the faces and actions of their makers and musicians. Visitors need to be able to situate themselves within the represented information in order to resonate with our messages. Without creating opportunities for visitors to step into musical stories, we stand little chance of connection, 
identification, and investment in our collections and institutions. Looking forward, how are museum professionals responding to the need for visitorcentric interpretation? In my own workplaces I have seen firsthand evidence of how new paradigms create excitement and engagement for visitors. 


\section{References}

Bates, Elliot. 2012. "The Social Life of Musical Instruments." Ethnomusicology 56(3): 363-395.

Burns, Thomas J. and Theresa A. Martinez. 1993. "Pedagogy and Popular Music." Humboldt Journal of Social Relations 19(1): 117-129.

Ceribašić, Naila. 2000. "Defining Women and Men in the Context of War: Images in Croatian Popular Music in the 1990s." in Music and Gender, edited by Pirkko Moisala and Beverley Diamond, 219-238. Urbana and Chicago: University of Illinois Press.

Ceribašić, Naila and Erica Haskell, eds. 2006. Shared Musics and Minority Identities: Papers from the Third Meeting of the "Music and Minorities" Study Group of the International Council for Traditional Music (ICTM), Roc, Croatia, 2004. Zagreb: Institute of Ethnology and Folklore Research.

Falk, John H. 2009. "Identity and the Museum Visitor Experience." Walnut Creek: West Coast Press, Inc.

Falk, John H. and Lynn D. Dierking. 2004. "The Contextual Model of Learning." In Gail Anderson, ed., Reinventing the Museum: Historical and Contemporary Perspectives on the Paradigm Shift. Lanham: AltaMira Press. 139-142.

- 1992. The Museum Experience. Washington: Whalesack Books/ Howells House.

Frith, Simon. 1996. Performing Rites: On the Value of Popular Music. Cambridge: Harvard University Press.

Higgins, Lee. 2012. Community Music: In Theory and Practice. New York: Oxford University Press.

"ICTM Study Group on Applied Ethnomusicology." < http://www.ictmusic. org/group/ictm-study-group-applied-ethnomusicology>

Kartomi, Margaret. 1990. On Concepts and Classifications of Musical Instruments. Chicago: The University of Chicago Press.

Krüger, Simone, 2009. "The Ethnomusicologist as Pedagogue: Disciplining Ethnomusicology in the United Kingdom." The World of Music 51(3): $139-170$

Lindsey, Rebecca and Allen Roda. 2014. "Raja Sourindro Mohun Tagore's Contribution to the Met: The Legacy of an Indian Renaissance Man of Indian Music." The Newsletter of the American Musical Instrument Society 43(2): 24-25.

Mantie, Roger. 2013 "A Comparison of 'Popular Music Pedagogy' Discourses." Journal of Research in Music Education 61(3): 334-352.

McCarthy, Cameron et al. 1999. "Introduction: Anxiety and Celebration: 
Popular Music and Youth Identities at the End of the Century." Counterpoints 96:1-16.

Pettan, Svanibor. 2007. "Balkan Boundaries and How to Cross Them." In Balkan Popular Culture and the Ottoman Ecumene: Music, Image, and Regional Political Discourse, edited by D. Buchanan, 365-383. Lanham: The Scarecrow Press, Inc.

Seeman, Sonia. 2012. "Macedonian Čalgija: A Musical Refashioning of National Identity." Ethnomusicology Forum 21(3): 295-326.

Simon, Nina. 2010. The Participatory Museum. Santa Cruz: Museum 2.0. Skramstad, Harold. 1999 "An Agenda for Museums in the Twenty-first Century." Daedulus 128(3): 109-128.

Slobin, Mark, ed. 1996. Retuning Culture: Musical Changes in Central and Eastern Europe. Durham: Duke University Press.

Tilden, Freeman. 1957 (1977). Interpreting Our Heritage. Chapel Hill: University of North Carolina Press.

Titon, Jeff Todd. 1992. "Music, the Public Interest, and the Practice of Ethnomusicology." Ethnomusicology 36(3): 315-322.

Žanić, Ivo. 2007. Flag on the Mountain: A Political Anthropology of War in Croatia and Bosnia. London: Saqi Books.

Zemke-White, Kristin. 2006. "Issues and History in Popular Music' POPMUS 106 Learning Critical Theory by Exploring the Familiar." Australian Journal of American Studies 25(1): 115-124. 